\title{
O (Des)Acesso de Pessoas Transgêneras aos Serviços de Saúde no Recôncavo Baiano
}

\author{
Helena Moraes CORTES, Universidade Federal do Recôncavo da Bahia \\ Ligia Maffei CARNEVALLI, Universidade Federal do Recôncavo da Bahia \\ Lorena Moura Pontes ARAÚJO, Universidade Federal do Recôncavo da Bahia \\ Paula Hayasi PINHO, Universidade Federal do Recôncavo da Bahia
}

O acesso em saúde pode ser entendido como a "porta de entrada" que facilita a utilização do sistema de saúde pelos cidadãos. Apesar da existência de políticas públicas para garantir uma saúde com mais equidade e qualidade para a população transgênera, ainda é possível notar a permanência de barreiras simbólicas, socioeconômicas e técnicas no acesso. O objetivo deste artigo é analisar o acesso de pessoas transgêneras aos serviços de saúde de um município do Recôncavo da Bahia. Trata-se de um estudo de abordagem qualitativa, descritivo e exploratório, no qual utilizou-se a técnica snowball ou "bola de neve", para a captação dos participantes. Os dados foram coletados por meio de entrevistas semiestruturadas e diários de campos e analisados por análise temática. A partir desta, emergiu a categoria empírica denominada acesso ao serviço de saúde, que se dividiu em três subcategorias a serem discutidas: conhecimento dos profissionais de saúde sobre a transgeneridade, Atendimento à pessoa transgênera no serviço de saúde e Utilização dos serviços de saúde. Por meio das falas dos entrevistados pôde-se perceber que a falta de capacitação dos profissionais de saúde em relação à transgeneridade mostrouse como importante barreira no acesso à saúde desta população. Como consequência, temos a perpetuação de estigmas e preconceitos dentro do serviço de saúde, resultantes de uma construção social patologizante, o que gera atendimentos precários e o consequente afastamento desta população dos serviços de saúde.

Palavras-Chave: Serviços de Saúde. População Transgênera. Acesso. 


\section{Introdução}

No que se refere à vivência de gênero, culturalmente, há uma imposição de papéis e comportamentos específicos para cada gênero, criando-se, assim, um padrão normativo. As pessoas transgêneras são aquelas que não se identificam com o gênero que lhe foi atribuído no nascimento com base no sexo biológico aparente, sofrendo, constantemente, preconceitos e sendo estigmatizadas por fugirem das normas exigidas (SPIZZIRRI; ANKIER; ABDO, 2017). Como herança de uma sociedade machista, tais preconceitos se estendem, à diversas áreas como a educacional, mercado de trabalho, família, religião e, também, aos serviços de saúde, o que torna essa população marginalizada e excluída socialmente (FERREIRA et al, 2018).

Desde a Constituição da República de 1988, o acesso e a utilização dos serviços de saúde foram estabelecidos como direito à toda população brasileira (SILVA; LUIZ; BAHIA, 2019). O acesso em saúde, segundo Assis e Jesus (2012), pode ser entendido como a "porta de entrada" (p. 2870) que facilita a utilização do sistema de saúde pelos cidadãos e pode ser influenciado por variáveis como: a disponibilidade dos serviços, a acessibilidade, a aceitabilidade e a capacidade financeira dos usuários. Ademais, esse acesso deveria seguir os três princípios básicos do Sistema Único de Saúde (SUS) que são: a universalidade, a integralidade e a equidade - mas observa-se, até então, uma heterogeneidade nos serviços e atendimentos à população transgênera

$\mathrm{Na}$ tentativa de garantir um acesso à saúde com mais equidade $\mathrm{e}$ qualidade, o Ministério da Saúde (MS) sancionou, em 2011, a Política Nacional de Saúde Integral de Lésbicas, Gays, Bissexuais, Travestis e Transexuais (LGBT), que contém princípios e diretrizes que visam reduzir a discriminação desse grupo nos atendimentos desde a atenção básica até a atenção especializada, compreendendo suas demandas populacionais (BRASIL, 2013). Ainda, devido à grande demanda dos Movimentos Sociais LGBT, a população trans obteve algumas conquistas como a ampliação do acesso ao processo transexualizador, foram incluídas a hormonioterapia e cirurgias como a mastectomia e histerectomia. Houve a criação dos centros ambulatoriais, para fazer o acompanhamento pré e pós-operatório, além do direito ao uso do nome social, de acordo com a portaria $\mathrm{n}^{0} 2.803$, de 19 de novembro de 2013 (Brasil, 2013).

Ainda, no ano de 2018, a Organização Mundial da Saúde realocou a incongruência de gênero do capítulo de transtornos mentais para o capítulo de condições relacionadas à saúde sexual, na Classificação 
Internacional de Doenças (CID-11), significando um avanço no que se refere à despatologização da transgeneridade (LEITE; LERNER, 2019). Entretanto, apesar de todas as conquistas recentes, ainda é possível notar a permanência de barreiras simbólicas, socioeconômicas e técnicas, que afastam a população transgênera dos serviços de saúde. Como exemplo disto, percebe-se, comumente, o desrespeito ao nome social, o preconceito à variabilidade de gênero e a falta de acolhimento às pessoas trans, que, muitas vezes, partem dos próprios profissionais de saúde, por não estarem preparados para atender às demandas transespecíficas (SPIZZIRRI; ANKIER; ABDO, 2017).

Portanto, o objetivo deste artigo é compreender como se dá o acesso de pessoas transgêneras aos serviços de saúde em um município do Recôncavo da Bahia.

\section{Desenvolvimento}

\section{Métodos}

Trata-se de um estudo de abordagem qualitativa, descritivo e exploratório. Utilizou-se a técnica snowball ou "bola de neve", para a captação dos participantes, que é útil quando se pretende trabalhar com questões específicas e grupos sociais difíceis de serem acessados. Nessa abordagem, não se tem como prever quantas pessoas participarão do estudo, pois inicialmente, parte-se de um indivíduo que o autor chama de semente e, por meio dele cria-se uma rede de referências (Vinuto J, 2014).

Sendo assim, partiu-se de uma unidade de um Centro de Testagem e Aconselhamento (CTA) de uma cidade do recôncavo baiano, com o objetivo de solicitar que o coordenador do serviço indicasse pessoas transgêneras para participarem deste estudo. As participantes denominadas "sementes iniciais" desta pesquisa foram duas mulheres transgêneras, indicadas pela coordenação do CTA, que apesar de não aceitarem participar da coleta de dados, indicaram informantes que eram pessoas ligadas a um grupo de um movimento social de Lésbicas Gays Bissexuais, Transsexuais, Queer, Intersexo e mais (LGBTQI+) do município e que, conheciam pessoas transgêneras, o que possibilitou o contato e convite a outras pessoas transgêneras.

Ao todo foi formada uma rede de referência composta por 44 pessoas, das quais 14 se auto reconheciam como pessoas transgêneras, aceitaram participar da pesquisa e foram entrevistadas. Os critérios de 
inclusão para participar da entrevista foram: pessoas que se reconhecem como transgêneras (transexuais, transgêneras, mulheres trans, homens trans, trans não-binários e travestis), maiores de 21 anos e, que residissem em um determinado município do Recôncavo da Bahia.

O ponto de saturação foi atingido quando os novos entrevistados passaram a repetir os conteúdos já obtidos em entrevistas anteriores, sem acrescentar novas informações relevantes à pesquisa ou indicaram pessoas que já tinham sido contatadas.

Para a coleta dos dados utilizou-se entrevistas semiestruturadas (identificadas como: E01, E02...E14) e diários de campos (identificadas como: D01, Do2 ... D14). A coleta dos dados foi realizada entre julho a agosto de 2018. Para análise dos dados utilizou-se a análise temática que, seguiu os seguintes passos: pré-análise, exploração do material, tratamento dos resultados obtidos e interpretação dos dados (Minayo, 2007).

Foram respeitados os princípios éticos em todas as etapas da pesquisa, de acordo com a resolução $\mathrm{n}^{0} 580 / 2018$ do Conselho Nacional de Saúde, do MS. A pesquisa que deu origem a este artigo faz parte de um recorte de um projeto maior intitulado "Caracterização sociodemográfica de pessoas transgêneras moradoras de um município do Recôncavo da Bahia”, aprovada no Comitê de Ética em Pesquisas (CEP) da Universidade Federal do Recôncavo da Bahia sob o CAAE 88518718.0.0000.0056.

\section{Resultados e Discussão}

Entre os participantes do estudo, verificou-se predomínio de mulheres transgêneras, solteiras e com trabalho informal, conforme os dados distribuídos na Tabela 1. 
Helena Moraes CORTES, Ligia Maffei CARNEVALLI, Lorena Moura Pontes ARAÚJO, Paula Hayasi PINHO.

Tabela 1 - Caracterização sociodemográfica de pessoas transgêneras em um município do recôncavo baiano

\begin{tabular}{|c|c|c|c|}
\hline \multicolumn{4}{|c|}{ Variáveis $(n=14)$} \\
\hline IDADE & $\mathbf{N}$ & ESTADO CIVIL & $\mathbf{N}$ \\
\hline $20-29$ anos & 7 & Solteiras & 12 \\
\hline $30-44$ anos & 7 & Casadas & 2 \\
\hline GÊNERO & $\mathbf{N}$ & USO DE DROGAS & $\mathbf{N}$ \\
\hline Homens transgêneros & 3 & Álcool & 5 \\
\hline Mulheres transgêneras & 8 & Tabaco & 1 \\
\hline Travestis & 2 & Álcool e tabaco & 1 \\
\hline Não sabe & 1 & Não utilizam & 7 \\
\hline $\begin{array}{l}\text { ORIENTAÇÃO } \\
\text { SEXUAL }\end{array}$ & $\mathbf{N}$ & $\begin{array}{l}\text { MERCADO DE } \\
\text { TRABALHO }\end{array}$ & $\mathbf{N}$ \\
\hline Heterossexuais & 10 & Não trabalham & 3 \\
\hline Homossexuais & 3 & Trabalho informal & 7 \\
\hline Não sabe & 1 & Trabalho formal & 4 \\
\hline RAÇA & $\mathbf{N}$ & ESCOLARIDADE & $\mathbf{N}$ \\
\hline Amarela & 1 & Ensino Superior & 2 \\
\hline Morena & 3 & incompleto & 5 \\
\hline Negra & 7 & Ensino médio completo & 4 \\
\hline Parda & 2 & Ensino médio incompleto & 1 \\
\hline Branca & 1 & $\begin{array}{c}\text { Ensino fundamental } \\
\text { completo } \\
\text { Ensino fundamental } \\
\text { incompleto }\end{array}$ & 1 \\
\hline RELIGIÃO & $\mathbf{N}$ & $\begin{array}{l}\text { POSSUEM PLANO DE } \\
\text { SAÚDE }\end{array}$ & $\mathbf{N}$ \\
\hline Candomblé & 5 & Sim & 1 \\
\hline Bruxa satânica & 1 & Não & 13 \\
\hline Católicos & 3 & TRATAMENTO & $\mathbf{N}$ \\
\hline Sem religião & 3 & HORMONAL & \\
\hline Espírita & 1 & Com acompanhamento & 5 \\
\hline Matriz africana & 1 & Por conta própria & 5 \\
\hline & & Nunca fez & 4 \\
\hline
\end{tabular}

Fonte: Elaboração das Autoras. 
A partir da análise dos dados emergiu a categoria empírica acesso ao serviço de saúde que se dividiu em três subcategorias, a serem discutidas: Conhecimento dos profissionais de saúde sobre a transgeneridade; atendimento à pessoa transgênera no serviço de saúde e utilização dos serviços de saúde.

O acesso à saúde, especialmente no contexto das (trans)especificidades, remete a uma gama de questões, entre estas a disponibilização de serviços, atendimento e respeito aos direitos humanos. Quando pensamos sobre a população transgênera, deve-se levar em conta que a discriminação e o estigma presentes na sociedade, além da inserção muito recente de políticas de saúde voltadas a este público no SUS, impactam diretamente na assistência à saúde integral desta população.

\section{Conhecimento dos profissionais de saúde sobre a transgeneridade}

Nas falas dos entrevistados, o conhecimento dos profissionais de saúde sobre a transgeneridade mostrou ser um dos desafios encontrados pelas pessoas trans em busca dos serviços de saúde:

Eo5: Eu acho que falta conhecimento deles [...] Sobre as trans. [...] Eles devem procurar saber tudo sobre uma trans, antes de atender uma.

E14: É uma dificuldade minha, uma questão individual que eu às vezes, sinto um pouco constrangido em procurar, justamente por essa falta de preparo no atendimento. [...] porque o acesso tá livre a todos e as pessoas tem que ir até lá, agora o problema é quando chega lá como vai ser recebido, em questão da preparação.

E14: Eles não conhecem, não sabem e não estão preparados para atenderem pessoas com essa demanda. [...] Nós como militantes recebemos as queixas das pessoas que precisam desses serviços. Tem posto de saúde [UBS] aí que se um trans chegar lá e disser que quer ser atendido pelo nome social, que é uma lei federal com portaria estadual, eles não 
sabem que o trans tem esse direito, apesar de estar no Jornal Nacional.

Eo7: Não, eles não sabem. Porque assim, pelo tratamento, pelo jeito... não sabe. O jeito de falar, o respeito. Não insistir em chamar de ele, "Óh ele, falta ele pra atender óh", não, chamar pelo nome social, chamar por ela (...).

O despreparo dos profissionais de saúde é entendido pelos entrevistados como uma falha na formação e educação permanente dos profissionais sobre a temática:

Eo9: [...] eu acho que já começa na própria faculdade, um afastamento, então quando cai na real: "Poxa, eu detesto viado. Eu detesto negro." E aí você tá lá na unidade de saúde e você tem que tá com um negro ou com um homossexual, entendeu?! [...] Eu acho que essa parte mais mesmo de preparar os profissionais. Essa parceria, já que a universidade, esse universo do conhecimento, que prepara esse povo para trabalhar nas Unidades [serviços de saúde] é que deveria ser mais preparado para sair pra lá.

E14: É investir em capacitação. Cursos, capacitações e eles fazem tantas capacitações com os profissionais, mas a gente não vê treinamento para o atendimento ao público LGBT dos profissionais de saúde. Não tem.

Eo1: [...] eu acho que a educação em saúde é, nesse momento, uma necessidade [...] com relação ao processo transexualizador, com relação à identidade de gênero, é o que pode ser feito pra melhorar o atendimento e, a busca da população nas Unidades [UBS].

Quando tratamos da qualificação profissional, há programas, planos e cursos online desenvolvidos para tal propósito. No próprio programa de saúde integral da população LGBT, instituído em 2011, está incluído em suas diretrizes a qualificação da rede de serviços do SUS e a inclusão da discussão sobre enfrentamento às discriminações nos momentos de educação permanente de gestores, trabalhadores de saúde e membros dos conselhos de saúde (BRASIL, 2011). 
Em 2013, a portaria de redefinição do processo transexualizador também trouxe em suas diretrizes o acolhimento e a humanização do atendimento, acompanhado da sensibilização dos trabalhadores e usuários das unidades de saúde, na intenção de existir o respeito às transespecificidades em toda a rede de saúde (BRASIL, 2013).

Entretanto, apesar dessas iniciativas para a formação e capacitação profissional, no cotidiano dos serviços de saúde, essa mudança na educação dos trabalhadores parece ainda não ser uma realidade. Os currículos dos cursos de graduação da maior parte das universidades não se adequaram a este cenário, enquanto a educação permanente direcionada aos profissionais, proposta nas portarias e políticas não é eficiente no seu alcance, ficando muito dependente da iniciativa do próprio profissional que atua no cotidiano dos serviços (MARINHO, 2014; NEGREIROS et al, 2019).

Para além do alcance e efetividade das políticas públicas, é premente compreender que a saúde da população trans envolve mais do que conhecimento técnico-científico, pois está pautada em um contexto sociocultural de discriminação, patologização de suas identidades e exclusão social. Por esse motivo, a educação sobre a saúde dessa população perpassa, para além da técnica, pela sensibilização e conscientização de tais particularidades (RAIMONDI; MOREIRA; BARROS, 2019), como relatou um dos entrevistados:

Eo1: Eles não entendem porquê que aquela pessoa tá se identificando como pessoa transexual. Não respeitam o nome, não respeitam a opinião do sujeito, né, por que o sujeito tá procurando a Unidade de Saúde pra fazer aquele tratamento, enfim, não tem um acompanhamento, de um modo geral. Eles não entendem, de uma forma geral, o que é que aquele sujeito representa.

No entanto, o ensino em saúde nas universidades ainda é baseado em uma visão reducionista, biologicista, heteronormativa, e patologizante, a qual não abre margens para a reflexão sobre as características da população trans, além de não trabalhar de forma efetiva as normativas e leis que instituem direitos às populações em vulnerabilidade social (NEGREIROS et al., 2019), favorecendo o contexto de desqualificação e desrespeito por parte dos profissionais de saúde. A este respeito, Cortes (2018) destaca a necessidade de maiores investimentos em pesquisas científicas que abordem o fenômeno da 
transgeneridade em suas múltiplas dimensões, o incremento de educação permanente nos serviços de saúde com o intuito de melhorar e otimizar o acesso, privilegiando a saúde integral da pessoa trans e suas particularidades, minimizando barreiras de acesso, além da inclusão da temática nos currículos dos cursos de saúde. Hatje (2019), contudo, evidenciou experiências exitosas de Grupos de Pesquisa cadastrados no Conselho Nacional de Desenvolvimento Científico e Tecnológico (CNPq) que tem se preocupado com o ensino de transgeneridades nos currículos de graduação.

É importante compreender ainda, que a maior parte dos esforços são voltados para a construção de políticas para a população LGBT, ou seja, há uma escassez de políticas públicas específicas para a população trans. Isso, porque ao manter o grupo LGBT sempre interligado nas políticas de saúde, limita-se os conteúdos ensinados às questões, quase que exclusivamente, de orientação e educação sexual. No entanto, a identidade de gênero perpassa por espaços diferentes da orientação sexual, assim, uma educação baseada nestes conceitos tende a reduzir o entendimento das necessidades da população trans e a compreensão da totalidade desses sujeitos (CHAGAS, 2017; BONASSI et al., 2015)

Dessa forma, este cenário de poucos investimentos em políticas públicas específicas, conscientização, formação e educação permanente para profissionais de saúde, resulta em uma prática pautada em conhecimentos tradicionais, estigmas e preconceitos, produzindo mais adoecimento do que acesso e saúde a esta população (NASCIMENTO, SOUSA E BARROS, 2018).

\section{Atendimento à pessoa transgênera no serviço de saúde}

Nesta subcategoria, o preconceito e a discriminação por parte dos profissionais de saúde esteve presente em muitos relatos, quando os participantes foram questionados sobre os atendimentos já vivenciados nos serviços de saúde:

Eo1: Quando a gente entra na Unidade [UBS], e diz que é uma pessoa trans, as pessoas não sabem lidar com isso, quando a gente diz que é um homem, mas que precisa de um atendimento ginecológico, causa um estranhamento, se a gente diz que o nome é "xis", fulano "Entrevistado o1", mas 
na identidade é fulana, o primeiro movimento é eles dizerem "ah, mas aqui está dizendo que você é fulana, então você vai ser chamado como fulana". Então não facilita na portaria, não facilita na secretaria, não facilita no atendimento, não facilita nas especialidades, não facilita de jeito nenhum, em lugar nenhum.

Eo2: Eu fui com muita falta de ar e eu cheguei e falei na emergência [do hospital de referência na região] e todo mundo viu que eu estava na emergência, que eu estava com falta de ar, mas não me atenderam, me deixaram. Na verdade, de primeira vieram me atenderam normal, a moça quando percebeu que eu era transgênera ficou travada $e$ saiu para trás do balcão e, eu fiquei lá com falta de ar.

Eo6: Eles falam nome civil, aí quando vê, chega a "Entrevistada o6" aí tem uns deles que começam a ter crítica ainda. A gente chamou um homem e veio uma mulher?! Ah não, não veio uma mulher, veio um homem querendo ser mulher a "pulso". Aí depois eles começam a falar "não... é um gay, não... é um viadinho... é uma outra coisa que não existe”. Por isso, eles não estão preparados ainda... é o preconceito, a homofobia dentro deles mesmo.

Eo7: A última vez foi no Hospital $X,[. .$.$] até que não$ demorou de atender porque foi um caso de emergência, mas sabe sempre... [...] não é um tratamento como trata uma mulher, como trata um homem, sabe?! Sempre tem aquele desprezo, aquele preconceito, aquele racismo. Como eu tô te falando, é o tratamento horrível, então... eu acho que assim... pelo fato de eu ser uma mulher trans dificulta, entendeu?!

Apreende-se por meio das frases temáticas que ocorrem violências no atendimento às pessoas trans. A falta de acolhimento, o desrespeito, a consequente dificuldade no desenvolvimento do vínculo e a qualidade da assistência que foram verificadas são barreiras técnicas que resultam no afastamento dos usuários do serviço de saúde, sobretudo quando se considera a Atenção Primária em Saúde, por intermédio das UBS's como portas de entrada e ponto de atenção mais próximas da 
comunidade, e que precisam representar um espaço de acolhimento, escuta e atenção integral à saúde dos usuários (LIMA et al., 2019; PEREIRA, CHAZAN, 2019).

Além de questões técnicas, barreiras simbólicas - com origens para além do campo da saúde - possuem grande influência quando se debate sobre o (des) atendimento à população trans e, consequentemente, ao (des) acesso desta ao serviço de saúde (PEREIRA E CHAZAN, 2019). Esta barreira está relacionada à cultura, ao sistema de crenças de uma sociedade e às subjetividades de cada indivíduo (ASSIS; JESUS, 2012).

Assim, para a compreensão desta dimensão deve-se entender que o gênero está relacionado à construção subjetiva do indivíduo, seu desejo de se expressar e de estar no mundo, sendo, também, influenciado pela cultura, ou seja, o gênero é socialmente construído. Contraditoriamente, estamos em uma sociedade que julga o gênero a partir de uma visão binária, heteronormativa e limitante, que resulta em imposições e fronteiras aos sujeitos e aos corpos (FERNANDES, 2019). E a partir da repetição destas normas, como ensina Judith Butler (2006) é que as identidades se desenvolvem (ARÁN; JÚNIOR, 2007).

É justamente essa ideia de gênero (binária, heteronormativa, limitante) difundida na sociedade que gera sofrimento para indivíduos transgêneros e conflitos nos serviços de saúde, pois são sujeitos que vão de encontro a essa norma, por meio de seus corpos, de sua expressão e de sua individualidade, mas que são (des)atendidos e (des)cuidados em um ambiente normativo, a partir de uma prática biomédica (MAIA; PIRES, 2018).

Quando os profissionais exercem suas práticas dentro dessa perspectiva limitante de compreensão do gênero, tem-se um serviço de saúde que opera em uma lógica excludente e patologizante, que perpetua e reforça os estigmas e preconceitos, ou seja, serviços que, para além de dificuldades técnicas no acesso, representam espaços não acolhedores, que desrespeitam subjetividades, corpos e expressões, resultando em situações constrangedoras e no afastamento do indivíduo transgênero desses espaços (PEREIRA E CHAZAN, 2019; ROGERS et al., 2016). Essas atitudes, dentro dos serviços de saúde vão contra os princípios de universalidade, integralidade e equidade do SUS, além de ir contra os princípios éticos dos profissionais de saúde, negando a autonomia e a liberdade de expressão dos sujeitos e impondo-lhes determinado juízo de valor (SANTOS et al., 2015).

Apesar de predominarem os relatos de desrespeito, mais de um entrevistado alegou ter experiências boas com os serviços de saúde, 
sobretudo com as unidades básicas de saúde (UBS), queixando-se apenas de questões estruturais do SUS:

Eo3: Sempre quando eu vou, eu sempre fui bem atendido [na UBS]. Nunca fui assim maltratado não. É só assim a demora de espera, mas não sei sempre fui atendido bem.

Eo4: Muito bem. Eles são... eles ficam muito bem quando eu vou lá. E as meninas me tratam super bem.

Eo5: Desde a primeira vez que eu fui lá no posto [UBS], eu sempre fui tratada bem, como mulher, que eles perguntam primeiro o nome social e tudo, da gente, normal, como mulher mesmo.

Eo1: Ele [médico] faz o movimento de dizer para as meninas que não é pra me chamar pelo nome civil, que é pra mudar a minha ficha, é... dizer que na minha ficha não é pra usar meu nome civil porque não precisa, porque já tem uma lei que garante.

E10: Todas as enfermeiras me adoram, eu sou tratada com bastante respeito, é tanto que botam meu nome social na minha receita e no planejamento familiar, é tanto que eu tomo injeção de três meses lá, que eu fiz o cartão [cartão do SUS] no serviço do SUS do meu bairro, no bairro da minha mãe que é o bairro $X$, é ótimo, de enfermeira a médico, me tratam tudo super bem e, me chamam pelo meu nome social.

Este cenário corrobora com Monteiro e Brigeiro (2019) e Roncon et al. (2018), ao destacarem o respeito e o reconhecimento à identidade de gênero do sujeito; o conhecimento, respeito e uso do nome social; o acolhimento e a capacitação profissional sobre a temática de gênero e transgeneridades como dimensões que caracterizam um bom atendimento nos serviços de saúde para as pessoas trans e suas particularidades.

Mesmo havendo relatos que fizeram referência ao bom atendimento nos serviços de saúde, o cenário expressado nas falas da maioria dos participantes configurou-se como uma perpetuação da violência já vivida por esta população em diversos âmbitos da sociedade, resultando, neste 
contexto, na negação ao acesso à saúde. Concordamos com a concepção de Fagundes (2016) quando afirmou que a violação de direitos, o desrespeito, a exposição e os atendimentos precários são resultados de uma construção social patologizante que trabalha a favor da edificação de normas e da exclusão de identidades desviantes destas.

\section{Utilização do sistema de saúde}

Dentro desta subcategoria temática, foram elencados relatos para facilitar a compreensão dos fatores que influenciam, ou não, na procura aos serviços de saúde. Foi possível notar sensações de insegurança e receio dos participantes quanto a ocorrerem possíveis situações desrespeitosas e constrangedoras que fazem com que o serviço de saúde não seja procurado por eles:

Eo2: Eu não fiz o processo transexualizador [...] eu não vou no posto [UBS], eu não procuro ir e porque, [...] eu não ia ter coragem de conversar, a não ser se fosse para uma outra mulher transexual ou uma mulher cis que acaba entendendo a gente. Então, eu não fiz por conta disso. Eu não fui nem ainda fazer carteira do SUS [cartão do SUS].

E14: Eu, muitas vezes, me recuso de procurar determinados serviços como o CTA, se precisar. Que eu não venha a precisar [risos], mas até a título de informação, para buscar alguma informação eu fico acanhado, como dizem as pessoas, de procurar as pessoas e de imaginar como será que vou ser recebido e tratar desse assunto [processo transexualizador no âmbito do SUS].

Do2: Ela refere não ter plano de saúde privado, mas também não utiliza o SUS, não tem nem o cartão do SUS. Disse que evita pois não se sente à vontade. Confidenciou que evita ir ao comércio, e não fala que quando frequenta algum mercado, pede para o marido acompanhá-la e refere não gostar muito da voz [por ter um tom grave] e não se sente confortável com sua feição [diz que os traços faciais não são femininos], embora se aceite. 
Eo9: Quando já houve vezes de eu precisar do SUS, ah... o momento do nome... isso que causa na verdade é um certo medo, um desespero. Às vezes, a gente nem procura já com medo mesmo. Querendo ou não, vai te identificar como pessoa trans, e não vai te ver como realmente "Entrevistada o9", porque na tua identidade querendo ou não, ela vai te segregar.

Essas sensações de insegurança e receio, apesar de estarem no contexto do sistema de saúde, nessas falas, são reflexos de preconceitos, estigmas e exclusões vivenciados pelas pessoas transgêneras em seu cotidiano, o que pode acarretar em grande sofrimento psíquico (SALUM, 2018). Isso faz com que, muitas vezes, esse grupo esteja associado a episódios de automutilação e, até mesmo suicídio, por causa da vulnerabilidade psicossocial na qual está inserido. Além disso, o uso abusivo de álcool, geralmente, se torna um suporte para essa população, de modo a conseguir tolerar as situações discriminatórias vividas no dia a dia (CORTES et al, 2019).

Ao buscarem o serviço de saúde, outros entrevistados relataram episódios de preconceitos advindos dos próprios profissionais, sendo mais uma barreira que causa o afastamento entre as pessoas transgêneras e o SUS:

Eo5: [...] Tem muitas amigas minhas que não vão consultar no médico, não vão no posto médico por causa disso, porque a maioria não trata elas como uma mulher trans.

E07: Utilizo o SUS, mas na maioria das vezes insiste em chamar de ele, entendeu?! É por isso que, muitas vezes eu evito de ir em um posto médico e no hospital pra não passar por esse constrangimento.

Eo1: Se você não é bem atendido na portaria da Unidade de Saúde, se as pessoas não te respeitam na portaria de saúde, você não vai querer buscar aquele serviço médico.

A percepção das pessoas transgêneras sobre a diferença de tratamento que há no sistema de saúde público e no sistema privado também emergiu das falas das participantes, sendo referido que nos serviços particulares há um maior respeito à transgeneridade: 
E12: Na verdade, eu tenho um pouco de medo de procurar porque eu tenho esse receio, assim de não... porque fica naquela coisa também de que quando você tá pagando, você se sente mais... como se aquela pessoa devesse um respeito a você, não sei o que esperar quando eu procurar assim... uma coisa relacionada... Público [serviço de saúde público] assim...

Eo9: Mas aí eu tô no sistema privado e não no sistema público [de saúde]. Talvez quem tá lá esteja mais preparada, por ter que atender pessoas como eu, e no SUS ainda não, né?!

Ferreira et al (2018) afirmam que no sistema de saúde privado, como há uma relação comercial, seus usuários têm uma concepção de que podem exigir um melhor atendimento, pois pagam, diretamente, pelo serviço.

Quanto às pessoas transgêneras, no município baiano estudado, Cortes et al (2019) trazem a perspectiva dessa população, que por ser marginalizada, inclusive, no mercado de trabalho são compelidas a inserir-se em empregos informais, por causa de entraves consequentes da transfobia, do preconceito e de discriminações que permeiam seus cotidianos de forma constante. Isso corrobora, mais uma vez, com a ideia de que todo cidadão tem o direito de ser atendido integralmente e universalmente no SUS a fim de atender suas demandas dentro do entendimento daquilo que é sua necessidade de saúde.

Com a redução das discriminações no serviço de saúde, as pessoas trans, provavelmente, passariam a utilizá-lo mais frequentemente, trazendo uma maior qualidade de vida a elas. Isso evidencia o fato de que, de uma forma geral, os profissionais de saúde necessitam passar por um processo de capacitação para compreenderem as demandas da população transgênera, de modo a sensibilizar-se para prestar um atendimento de forma mais humanizada (SALUM, 2018). 


\section{Considerações finais}

De uma forma geral, entende-se que o afastamento da população transgênera, no município estudado dos serviços de saúde, perpassa por um ciclo de violências e negação de identidades rotineiramente vivenciadas. A construção social que patologiza a identidade transgênera constrói estigmas e preconceitos que adentram os serviços, violentando e excluindo esta parcela da população.

Com a falta de uma formação adequada e de uma educação permanente sensível e eficaz, os profissionais de saúde levam para a micropolítica do fazer cotidiano, atitudes de desrespeito e mais do que isso, práticas reducionistas, inflexíveis e excludentes que não compreendem a profundidade da vulnerabilização que este público enfrenta rotineiramente.

Tais barreiras de acesso geram, muitas vezes, a supressão das pessoas trans dos serviços de saúde. E, além da exclusão social, este contexto impulsiona a uma busca por práticas clandestinas podendo resultar em complicações clínicas significativas no seu processo saúde doença.

Entende-se, a partir do exposto que, é necessária a inclusão da temática da atenção à saúde integral das pessoas transgêneras nos currículos de formação dos profissionais de saúde. Além disso, a educação permanente no contexto das redes de atenção à saúde, precisa ser efetiva desde a atenção primária à saúde até os níveis de maior complexidade.

No mais, compreender as vivências e experiências da população trans nos serviços de saúde permitem um entendimento maior do hiato que encontramos entre as políticas de saúde e as práticas que estão sendo concretizadas no cotidiano dos serviços. Acredita-se que estas compreensões podem alavancar práticas de saúde mais efetivas e sensíveis às pessoas transgêneras e suas transespecificidades, atendendo as suas demandas de saúde e no mínimo reduzindo o cenário de inequidades ora revelado.

\section{Referências}

ARÁN, Márcia; PEIXOTO JÚNIOR, Carlos Augusto. Subversões do desejo: sobre gênero e subjetividade em Judith Butler. Cadernos Pagu, [s.l.], n. 28, p.129-147, jun. 2007. Disponível em: 
<http://www.scielo.br/scielo.php?script=sci_arttext\&pid=So104-8333 2007000100007>. Acesso em: 10 out. 2019.

ASSIS, Marluce Maria Araújo; JESUS, Washington Luiz Abreu de. Acesso aos serviços de saúde: abordagens, conceitos, políticas e modelo de análise. Ciência \& Saúde Coletiva, [s.l.], v. 17, n. 11, p.2865-2875, nov. 2012. Disponível em: <http://www.scielo.br/scielo.php?script=sci_arttext\&pid=S1413-81232 012001100002\&lng=en\&nrm=iso\&tlng=pt > . Acesso em: 10 out. 2019.

BONASSI, Bruna Camillo et al. Mapped vulnerabilities, Located violences: Experiences of transvestites and transgender individuals in Brazil. Quaderns de Psicologia, [s.l.], v. 17, n. 3, p.83, 31 dez. 2015. Disponível em: <https://www.quadernsdepsicologia.cat/article/view/v17-n3camillo-dossantos-filgueiras-etal>. Acesso em: 12 out. 2019.

BRASIL. PORTARIA No 2.803, DE 19 DE NOVEMBRO DE 2013(*). Redefine e amplia o Processo Transexualizador no Sistema Único de Saúde (SUS). Diário Oficial da União. 21 Nov 2013. Seção 1. Página 25. Disponível

em: <http://bvsms.saude.gov.br/bvs/saudelegis/gm/2013/prt2803_19_11_ 2013.html>. Acesso em: o5 out. 2019.

BRASIL. PORTARIA No 2.836, DE $1^{\circ}$ DE DEZEMBRO DE 2011. Institui, no âmbito do Sistema Único de Saúde (SUS), a Política Nacional de Saúde Integral de Lésbicas, Gays, Bissexuais, Travestis e Transexuais (Política Nacional de Saúde Integral LGBT). Diário Oficial da União, Brasília, DF, 1 dez. 2011. Disponível em: <http://bvsms.saude.gov.br/bvs/saudelegis/gm/2011/prt2836_01_12_ 2011.html>. Acesso em 01 out. 2019.

Brasil. Ministério da Saúde. Secretaria de Gestão Estratégica e Participativa. Departamento de Apoio à Gestão Participativa. Política Nacional de Saúde Integral de Lésbicas, Gays, Bissexuais, Travestis e Transexuais / Ministério da Saúde, Secretaria de Gestão Estratégica e Participativa, Departamento de Apoio à Gestão Participativa. Brasília: 1. ed., 1. reimp. Ministério da Saúde, 2013. 32 p.

CHAGAS, Emmily Negrão. IDENTIDADE DE GÊNERO E POLÍTICAS PÚBLICAS: a invisibilidade da população trans no Brasil. VIII Jornada internacional de políticas públicas, 2017. Disponível em: 
<http://www.joinpp.ufma.br/jornadas/joinpp2017/pdfs/eixo6/identida dedegeneroepoliticaspublicasainvisibilidadedapopulacaotransnobrasil.p df $>$. Acesso em: 06 out. 2019.

CORTES, Helena Moraes et al. Vivências de mulheres transgêneras de um município do recôncavo da Bahia. Revista Eletrônica Acervo Enfermagem, [s.l.], v. 1, e1871, 23 out. 2019. Disponível em: <https://www.acervomais.com.br/index.php/enfermagem/article/view/ 1871/922>. Acesso em: 02 out. 2019.

CORTES, Helena Moraes. A transgeneridade feminina e os processos de mudanças corporais. Journal Of Nursing And Health, [s.l.], v. 8, n. 2, e188211, 29 set. 2018. Disponível em: <https://periodicos.ufpel.edu.br/ojs2/index.php/enfermagem/article/vi ew/14345>. Acesso em: 02 out. 2019.

FAGUNDES, Nagel de Oliveira. Transgeneridade e saúde: atendimentos discriminatórios contra pessoas transgêneras na política de saúde. 8op. 2016. Trabalho de Conclusão do Curso (Graduação em Serviço Social) Universidade Federal do Pampa, Campus São Borja, São Borja, 2016. Disponível em: <http://dspace.unipampa.edu.br/bitstream/riu/2239/1/Nagel\%20de\%2 oOliveira\%20Fagundes.pdf $>$. Acesso em: 13 out. 2019.

FERNANDES, Luís Antonio Bitante. Corpos que falam: Biopolítica e saúde LGBTQI. Fórum Linguístico, [s.l.], v. 16, n. 3, p.3983-3993, 22 out. 2019. Disponível em: <https://periodicos.ufsc.br/index.php/forum/article/view/19848412.2019v16n3p3983/41066 >. Acesso em: 11 out. 2019.

FERREIRA, Denis Goncalves et al. MEUS DIAS, MINHA SAÚDE: ESTUDO LOCAL SOBRE A REALIDADE SOCIAL E OS CUIDADOS COM A SAÚDE DE TRAVESTIS E TRANSEXUAIS EM MATO GROSSO. Connection Line - Revista Eletrônica do Univag, [s.l.], n. 18, p.69-88, 18 jun. 2018.

Disponível em: <https://www.periodicos.univag.com.br/index.php/CONNECTIONLIN E/article/view/820>. Acesso em: 02 out. 2019.

HATJE, Luis Felipe; PEREIRA, Lara Torrada; SILVA, Marcus Vinícius Tams da. Análise Dos Grupos de Pesquisa Cadastrados na Plataforma Lattes do CNPQ com Produção Científica Relacionada com a 
Transgeneridade. Revista Diversidade e Educação, Rio Grande, v. 7, n. 1, p.92-120, jun. 2019. Disponível em: $<$ https://periodicos.furg.br/divedu/article/view/9037/5985>. Acesso em: 11 out. 2019.

LEITE, Tatiana Clébicar; LERNER, Katia. Notícias sobre a nova classificação das identidades trans: uma análise das fontes citadas em reportagens publicadas no Brasil. Revista Eletrônica de Comunicação, Informação e Inovação em Saúde, [s.l.], v. 13, n. 2, p.314-329, 28 jun. 2019. Disponível em: <https://www.reciis.icict.fiocruz.br/index.php/reciis/article/view/1699 >. Acesso em: 2 nov. 2019.

LIMA, Átila Mourão et al. Atributos da Atenção Primária à Saúde e ferramentas de medicina de família no atendimento às diversidades sexual e de gênero: Relato de caso. Revista Brasileira de Medicina de Família e Comunidade, [s.l.], v. 14, n. 41, p.1785-1794, 15 ago. 2019. Disponível em: <https://rbmfc.org.br/rbmfc/article/view/1785 $>$. Acesso em: 10 out. 2019.

MAIA, Gabriela Felten da; PIRES, Gabriela. AS TRANSFORMAÇÕES NO DISPOSITIVO DA TRANSEXUALIDADE A PARTIR DA LUTA PELA DESPATOLOGIZAÇÃO. Seminário Internacional Demandas Sociais e Políticas Públicas na Sociedade Contemporânea: Mostra Internacional de Trabalhos Científicos, 2019. Disponível em: $<$ http://online.unisc.br/acadnet/anais/index.php/sidspp/article/view/1 8825>. Acesso em: 10 out. 2019.

MARINHO, Marina Melo Arruda. Análise da qualificação dos profissionais de saúde no âmbito da formação acadêmica dos estudantes de medicina de Brasília para o atendimento para a população LGBT no SUS. 2014. 24 f. TCC (Graduação) - Curso de Curso de Especialização em Gestão de Políticas Públicas em Gênero e Raça, Universidade de Brasília, Florianópolis, 2014. Disponível em: <https://bdm.unb.br/bitstream/10483/13208/1/2014_MarinaMeloArr udaMarinho.pdf $>$. Acesso em: 10 out. 2019.

MINAYO, Maria Cecília de Souza. O desafio do conhecimento: pesquisa qualitativa em saúde. pesquisa qualitativa em saúde. 10. ed. São Paulo: Hucitec, 2007. 406 p. 
MONTEIRO, Simone; BRIGEIRO, Mauro. Experiências de acesso de mulheres trans/travestis aos serviços de saúde: avanços, limites e tensões. Cadernos de Saúde Pública, [s.l.], v. 35, n. 4, 2019. Disponível em: <http://www.scielo.br/scielo.php?script=sci_arttext\&pid=S0102311X2019000400504\&tlng=pt>. Acesso em: 10 out. 2019.

MORE: Mecanismo online para referências. Versão 2.o. Florianópolis: UFSC Rexlab, 2013. Disponível em: <http://www.more.ufsc.br/>. Acesso em: 24 mar. 2020.

NASCIMENTO, Hosana Maria do; SOUSA, Junior Araujo; BARROS, Claudia Renata dos Santos. O atendimento em saúde a travestis e transexuais: revisão sistemática de literatura (2008-2017). Rebeh Revista Brasileira de Estudos da Homocultura, [s.1.], v. 1, n. 4, p.40-58, fev. 2019. Disponível em: <http://www.revistas.unilab.edu.br/index.php/rebeh/article/view/147> . Acesso em: 12 out. 2019.

NEGREIROS, Flávia Rachel Nogueira de et al. Saúde de Lésbicas, Gays, Bissexuais, Travestis e Transexuais: da Formação Médica à Atuação Profissional. Revista Brasileira de Educação Médica, [s.l.], v. 43, n. 1, p.23-31, mar. 2019. Disponível em: <http://www.scielo.br/scielo.php?script=sci_arttext\&pid=So10o55022019000100023\&lng $=\mathrm{en} \& \mathrm{nrm}=\mathrm{iso} \& \mathrm{tlng}=\mathrm{pt}>$. Acesso em: 2 out. 2019.

PEREIRA, Lourenço Barros de Carvalho; CHAZAN, Ana Cláudia Santos. O Acesso das Pessoas Transexuais e Travestis à Atenção Primária à Saúde: uma revisão integrativa. Revista Brasileira de Medicina de Família e Comunidade, [s.l.], v. 14, n. 41, p.1795, 14 maio 2019. Disponível em: <https://rbmfc.org.br/rbmfc/article/view/1795>. Acesso em: 2 out. 2019.

RAIMONDI, Gustavo Antonio; MOREIRA, Claudio; BARROS, Nelson Filice de. Gêneros e sexualidades na educação médica: entre o currículo oculto e a integralidade do cuidado. Saúde e Sociedade, [s.l.], v. 28, n. 3, p.198-209, set. 2019. Disponível em: <http://www.scielo.br/scielo.php?script=sci_arttext\&pid=So104$12902019000300198>$. Acesso em: 11 out. 2019. 
ROCON, Pablo Cardozo et al. O que esperam pessoas trans do Sistema Único de Saúde? Interface - Comunicação, Saúde, Educação, [s.l.], v. 22, n. 64, p.43-53, 7 dez. 2017. Disponível em: <http://www.scielo.br/scielo.php?script=sci_arttext\&pid=S141432832018000100043\&lng=en\&nrm=iso\&tlng=pt $>$. Acesso em: 8 out. 2019.

ROGERS, João et al. Pessoas Trans na Atenção Primária: análise preliminar da implantação no município de Florianópolis, 2015. Saúde \& Transformação Social, Florianópolis, v. 7, n. 3, p.49-58, set. 2016. Disponível em: <http://incubadora.periodicos.ufsc.br/index.php/saudeetransformacao/ article/view/4276/4647>. Acesso em: 9 out. 2019.

SALUM, Maria Eduarda Grams. Gestão do cuidado à pessoa trans na atenção primária à saúde. 2018. 58 f. TCC (Graduação) - Curso de Enfermagem, Universidade Federal de Santa Catarina, Florianópolis, 2018. Disponível em: <https://repositorio.ufsc.br/bitstream/handle/123456789/187181/TCC \%20Maria\%20Eduarda\%20Grams\%20Salum.pdf?sequence=1\&isAllowe $\mathrm{d}=\mathrm{y}>$. Acesso em: 02 out. 2019.

SANTOS, Adilson Ribeiro dos et al. Implicações bioéticas no atendimento de saúde ao público LGBTT. Revista Bioética, [s.l.], v. 23, n. 2, p.400-408, ago. 2015. Disponível em: <http://www.scielo.br/pdf/bioet/v23n2/19838034-bioet-23-2-0400.pdf >. Acesso em: 12 out. 2019.

SILVA, Carlos; LUIZ, Ronir Raggio; BAHIA, Ligia. Vinculação aos planos de saúde de menor abrangência e seu impacto na utilização da rede de serviços do SUS: uma análise a partir da Pesquisa Nacional de Saúde de 2013. Jornal Brasileiro de Economia da Saúde, [s.l.], v. 11, n. 2, p.135-141, ago. 2019. Disponível em: <https://pesquisa.bvsalud.org/portal/resource/pt/biblio1021110 >. Acesso em: 13 out. 2019.

SPIZZIRRI, Giancarlo; ANKIER, Cila; ABDO, Carmita Helena Najjar. Considerações sobre o atendimento aos indivíduos transgêneros. Diagnóstico e Tratamento, [s.l.], v. 4, n. 22, p.176-179, ago. 2017. Disponível em: <https://pesquisa.bvsalud.org/portal/resource/pt/biblio-875488>. Acesso em: 11 out. 2019 


\section{The (dis) access of transgender people to health services in the region of Bahia, Brazil}

RESUMEN/ABSTRACT: The access to health can be understood as the "gateway" that facilitates the use of the health system by the citizens. Despite the existence of policies to guarantee health with more equity and quality for the transgender population, it is still possible to note the permanence of symbolic, socioeconomic and technical barriers in access. The purpose of this article is to analyze the access of transgender people to health services in a municipality in the state of Bahia, Brazil. It is a qualitative, descriptive and exploratory approach, in which the snowball technique was used to capture participants. Data were collected through semi-structured interviews and field diaries and analyzed by thematic analysis. From this, the empirical category emerged, access to health service, which was divided into three subcategories to be discussed: knowledge of health professionals about the transgenerity, Assistance to transgender people in the health service and the use of health services. It was possible to perceive through the interviewees' statements, that the lack of training of health professionals in relation to transgenerity proved to be an important barrier to access to health for this population. As a consequence, we have the perpetuation of stigmas and prejudices within the health service, resulting from a pathologizing social construction, which generates precarious care and the consequent removal of this population from health services.

Palabras Clave/Keywords: Health Services. Transgender Population. Access.

Helena Moraes CORTES

Enfermeira. Doutora em Ciências pela EEUSP. Universidade Federal do Recôncavo da Bahia. Email: helenamoraescortes@gmail.com

Ligia Maffei CARNEVALLI

Bacharela em saúde. Acadêmica do curso de Medicina.

Universidade Federal do Recôncavo da Bahia.

Email:Imcarnevalli@gmail.com

Lorena Moura Pontes ARAÚJO

Bacharela em saúde. Acadêmica do curso de Medicina. Universidade Federal do Recôncavo da Bahia. Email: lorenamparaujo@gmail.com

Paula Hayasi PINHO

Psicóloga. Doutora em Ciências pela EEUSP. Universidade Federal do Recôncavo da Bahia. Email:phpinho@ufrb.edu.br

Recebido em: 30/o8/2020 Aprovado em: 27/01/2021 